\title{
LAS IDEAS SOBRE EL AMOR EN LAS TRAGEDIAS DE SÉNECA*
}

\author{
Emilio del Río. ** \\ Universidad de La Rioja
}

\begin{abstract}
RESUMEN. En las tragedias de Séneca el amor juega un papel importante y es un recurso dramático destacado: se plantea como una de las pasiones que desestabilizan al individuo. Los terrores elementales que amenazan con perturbar alguna vez la existencia humana (la muerte omnipresente, las pasiones y sus terribles efectos, la culpa voluntaria o involuntaria y la tiranía política) que dominan las tragedias son los que le preocupan en su prosa, pero mientras el Séneca prosista combate estos males con el estoicismo, las tragedias apenas van más allá de presentarlos, y no se alude a los remedios contra el mal: el aspecto positivo de la doctrina estoica es raro en las tragedias.
\end{abstract}

ABSTRACT. In Seneca's tragedies love plays an outstanding role and it is an important dramatic resource: It is one of the threatening passions of the individuals. The elementary fears that threaten to disturb the human existence (omnipresent death, the passions and their terrible effects, the voluntary or involuntary guiltness and politic tirany) that rule the tragedies are the main interest of prose, but while Seneca the prosist fights these evils with stoicism, the tragedies go hardly far beyond representing them, and it doesn't refers to remedia against the evil: the positive aspect of the stoic doctrine is not common in the tragedies.

Es indiscutible la base estoica de las tragedias de Séneca. Por importante que pueda ser la influencia de la tragedia griega, la concepción trágica de Séneca está básicamente condicionada por una determinada visión del mundo: la que le dan sus ideas filosóficas (aunque de ahí a decir que hayan sido compuestas como un programa de enseñanza estoica hay una gran distancia) ${ }^{1}$. Se trata, en las páginas que siguen, de

* El presente artículo surgió de una comunicación presentada, con el mismo título, al Congreso "Primeros Encuentros sobre el amor", organizado por el Área de Teoría de la Literatura del Departamento de Lingǘstica General e Hispánica de la Universidad de Zaragoza en septiembre de 1993. Recibido en la Redacción el 29 de octubre de 1994.

** Dr. en Filología Clásica (Latina) por la Universidad Complutense. Profesor Asociado de Filología Latina en la Universidad de La Rioja.

1. Como ya señaló Platón (Leyes, 7,817 a-b, ed. J.M. Pabón y M. Fernández Galiano, 2 t., Madrid, 1983-4), la aceptación absoluta de cualquier sistema metafísico coherente y exclusivo y la creación de la 


\section{EMILIO DEL RÍO}

comprobar, siquiera brevemente, la adecuación entre la ideas sobre el amor en sus obras filosóficas y su papel en el corpus dramático senecano.

Séneca no ha dedicado una obra específica al amor: sus obras en prosa son consolaciones a amigos y familiares, cartas de un estoicismo renovado - con otras influencias filosóficas, especialmente epicúreas y pitagóricas - a su amigo Lucilio; o tratan sobre la brevedad de la vida, sobre la felicidad, la constancia del sabio, la serenidad del alma, sobre la providencia, el ocio, la ira, la clemencia, sobre la amistad o los remedios contra la fortuna. No faltan, sin embargo, en todas ellas reflexiones sobre el amor, a las que nos refereriremos más adelante.

En sus tragedias el amor juega un papel importante y es un recurso dramático destacado: actúa como pasión desbordada y aniquiladora en Phaedra; pasión mezclada con odio en los celos de Medea (Medea vv. 579-582), de Clitemnestra (Agamemnon vv. 175, 178, 225) o de Deyanira (H.O. vv. 450-2); amor doloroso y furioso, arrebatado (Medea vv. 591-4), más difícil de vencer porque está enquistado en el corazón y conduce, fatalmente, al crimen (H.O. vv. 435-444). El amor en las tragedias se plantea como una de las pasiones que desestabilizan al individuo. Y es que cada una de las tragedias de Séneca, como bien señala Herington ${ }^{2}$, tiene un sentido coherente como estudio concentrado en uno o más de los terrores elementales que amenazan con perturbar alguna vez la existencia humana: la muerte omnipresente, las pasiones y sus terribles efectos, la culpa voluntaria o involuntaria y la tiranía política. Cada una de las tragedias está impregnada por completo de un espantoso ambiente de mal, como tal vez no lo esté ninguna otra obra de la literatura antigua: el acento de la obra se encuentra en el mal. Estos males que dominan las tragedias son los que le preocupan en su prosa, pero mientras el Séneca prosista combate estos males con el estoicismo, las tragedias ape-

tragedia se excluyen recíprocamente. En lo que respecta a estas obras de Séneca, estamos de acuerdo con J. Luque, que excluye una específica finalidad didáctica en las tragedias, lo que invalida sus valores didácticos, $c f$. su magnífica edición Séneca. Tragedias, Madrid: Gredos, t. 1, p. 35 . En la importantísima hegemonía del teatro de Séneca en la literatura europea jugó un papel muy importante la base doctrinal de su teatro y del resto de su obra. Séneca alcanzaba preeminencia sobre los trágicos griegos, y lo hacía precisamente por aquello por lo que sus dramas se apartan más de la tragedia helénica, su base estoica que tan bien encajaba dentro de las coordenadas de la moral cristiana, $c f$. R.G. Tanner, "Stoic Philosophy and Roman Tradition in Senecan Tragedy", Aufstieg und Niedergang der Römische Welt, New York-Berlín: Walter de Gruyter, 1985, pp. 1100-1133., E.Lefevre, "Die philosophische Bedeutung der Seneca-Tragödie am Beispiel des «Thyestes»", ibid., pp. 1263-1283. Del resto de la bibliografía destacan los trabajos de N. T. Pratt, "The stoic base of Senecan drama", TAPA, 79, (1948), pp. 1-11; E.C. Evans, "A stoic aspect of Senecan drama", TAPA, 81, (1950), pp. 164-184; J.F. Brandy, "A Study of the Stoicism in Senecan Tragedy", New York, 1958; J. C. García Borrón, "El senequismo en el teatro de Lucio Anneo Séneca", Revista de Filosofia 17, (1958), pp. 65-70; C.M. King, "Seneca's Hercules Oetaeus. A stoic interpretation of the Greek myth", $G \& R$, (1971), pp. 214-222; M. Cacciaglia, "L'etica stoica nei drammi di Seneca", RIL, 108, (1974), pp. 78-104; A. Pociña, "Finalidad didáctico-política de las tragedias de Séneca", Emerita, 44, (1976), pp. 279-301. El estoicismo en las tragedias de Séneca es tratado también por J. S. Lasso de la Vega, "Héroe griego y santo cristiano", en Ideales de la formación griega, Madrid, 1966, pp. 181-272 y De Sófocles a Brecht, Barcelona, 1971.

2. C. J. Herington en Historia de la literatura latina (Cambridge), E. J. Kenney y W. v. Clausen eds., Madrid, Gredos, 1989, trad. de Elena Bombín (1ª, Cambridge, 1982), p. 573. 
nas van más allá de presentarlos, y apenas se alude a los remedios contra el mal: el aspecto positivo de la doctrina estoica es raro en las tragedias, aunque la actitud mental de Séneca como estoico ejerce una influencia directa en su obra en casi todos los aspectos.

1. Las principales reflexiones sobre el amor en sus obras en prosa son las siguientes ${ }^{3}$ :

- Epistulae ad Lucilium 9, 11, similitud de amor y amistad:

- Epistulae ad Lucilium 35, 1, diferencia entre amor y amistad:

- Epistulae ad Lucilium 9, 6, cómo conseguir el amor.

- Epistulae ad Lucilium 47, 18, el amor no puede confundirse con el temor.

- De beneficiis 4, 19, 1, no se ama lo que se teme.

- Epistulae ad Lucilium 76, 20, hay que hacer, en aras de la virtud, lo que otros hacen movidos por la pasión amorosa.

- Epistulae ad Lucilium 105, 6, amor secreta producit.

- Epistulae ad Lucilium 35, 3, es placentero ver a, estar y conversar con los que amamos.

- Epistulae ad Lucilium 69, 3, nada se reaviva con más facilidad que el amor.

- Epistulae ad Lucilium 63, 11: deinde ne unum quidem nimis amauit qui plus quam unum amare non potuit.

- Epistulae ad Lucilium 116, 5, punto de vista de Panecio sobre el amor, aeque facilitas amoris quam difficultas nocet, que Séneca aplica, dice, a todas las pasiones.

- Epistulae ad Lucilium 18, 15, del amor puede surgir también la ira.

- De ira 2, 36, 6, la ira somete a todas las pasiones: acaba incluso con el más ardiente amor.

- Epistulae ad Lucilium 81, 12; 123, 15, sólo el hombre sabio entiende de amor.

- De clementia 2, 5, 2-3, no hay ninguna escuela más amable, ninguna más llena de amor por el hombre que la de los estoicos.

2. En cuanto a las Tragedias, Séneca recoge en ellas, por un lado, la creencia tradicional en la fatalidad y el carácter divino del amor:

- H.O. 472: vicit et superos Amor ("el amor ha vencido incluso a los dioses"), dice la nodriza ante el escepticismo de Deyanira, para quien Hércules será "el único ante quien se rinda y entregue sus despojos el amor, convirtiéndose en el último de los trabajos del Alcida" (vv. 473-4)

- Phaedra 112-128, la propia Fedra se refiere a la fatalidad de los amores de su familia, especialmente en los vv. 124-1284.

3. Hemos seguido las siguientes ediciones: Epistulae ad Lucilium, ed. L.D. Reynolds, Oxford, 2 t.,1965; Dialogi, ed. L.D. Reynolds, Oxford, 1977; De beneficiis, ed. F. Préchac, París, 2 t., 1972; De clementia, ed. C. Hosius, Leipzig, 1914; Tragoediae, ed. O. Zwierlein, Oxford, 1986.

4. cf. A. Ruiz de Elvira, Mitología clásica, Madrid, 1984 (1 $1^{\text {a }}$, 1975), p. 377-381. 
EMILIO DEL RÍO

- Phaedra 177-180, donde Fedra confiesa que "una loca pasión le fuerza a seguir el peor camino":

PH. Quae memoras scio

uera esse, nutrix; sed furor cogit sequi

peiora. uadit animus in praeceps sciens

remeatque frustra sana consilia appetens.

Aquí es donde más abiertamente se plantea el conflicto entre la pasión (furor) y la razón $(\text { ratio })^{5}$. Frente al optimismo socrático de que nadie es malo voluntariamente, Séneca se muestra aquí y en otras ocasiones pesimista. Pero este planteamiento, además de adecuarse al pensamiento filosófico de Séneca (cf. Epistulae ad Lucilium 94, 19; De beneficiis 5, 25, 5), representa también una resonancia de toda una tradición literaria (Eurípides, Medea 10796; Ovidio, Metamorfosis 7, $20 \mathrm{y} \mathrm{ss}^{7}$ ).

- Phaedra 184-194, especialmente los vv. 184-187:

quid ratio possit? uicit ac regnat furor,

potensque tota mente dominatur deus.

hic uolucer omni pollet in terra potens

ipsumque flammis torret indomitis Iouem.

El verso 184 refleja el poder total del amor: ha vencido y reina el furor, la pasión amorosa (este pensamiento se remonta a Eurípides — con cuyos dos Hipólitos se relaciona la Phaedra de Séneca ${ }^{8}$-, frag., $431^{9}$, y está presente también en Ovidio,

5. Sobre el furor en las tragedias de Séneca, $c f$. R. Glaesser, Untersuchung zum Furor-Begriff bei Lucan mit Berïcksichtigung der Tragödien Senecas, Frankfurt, 1984.

6. Eurípides, Hyppolytos, ed. W. S. Barrett, Oxford, 1964.

7. P. Ovidio, Metamorfosis, ed. A. Ruiz de Elvira, t. 2, Madrid, 1988.

8. Para P. Grimal, "L'originalité de Sénèque dans le tragédie de Phèdre", REL, 41, (1963), pp. 297 314 se reflejan en la Phaedra de Séneca no sólo los dos Hipólitos de Eurípides (el primero perdido; la Phaedra de Séneca ha servido para reconstruir esta obra perdida de Eurípides, $c f$. W.H. Friedrich, Euripides und Diphilos, Munich, 1953), sino también en la Fedra de Sófocles y la de Licofrón (las dos perdidas), y la Heroida cuarta de Ovidio. Un buen estudio de los distintos tratamientos del mito en Ch. Segal, "Seneca baroque: the death of Hyppolytus in Seneca, Ovid and Euripides", TAPA, 114, (1984), pp. 311-325. Para las fuentes de esta tragedia $c f$. especialmente R.J. Tarrant, "Senecan Drama and its Antecedents", HSPh, 82, (1978), pp. 213-263; también H.S. Moricca, "Le fonti della Fedra di Seneca", Studi italiani di Fil. Class., (1915), pp. 158-224; E. Paratore, "Sulla Phaedra di Seneca", Dioniso, 15, (1952), pp. 195-234; S. Mariner, "El sentido de la tragedia en Roma", Revista de la Universidad de Madrid, 13, (1964), pp. 463-492; Mª. D. Gallardo, "Análisis mitográfico y estético de la Fedra de Séneca"CFC, 5, (1973), pp. 63-107; E. Fantham, "Virgil's Dido and Seneca's Tragic Heroines", Greece and Rome, 2, 22, (1975), pp. 1-10; J. Gahan, "Imitatio and aemulatio in Seneca's Phaedra", Latomus, 46, (1987), pp. 380-387.

En cuanto a Eurípides, el amor es uno de los temas más frecuentes en sus tragedias: el tema de Putifar está presente en varias tragedias (Hipólito, Estenebea, Fénix y Peleo, y en obras que no nos han llegado se planteaban la sodomía, la pederastia o el incesto); no falta el tema de la mujer celosa (Medea, Hermíone); la mujer adúltera (Fedra, Estenebea, Aérope); o la joven deshonrada (Álope, Dánae, Antíope, Melanipa). 
Heroidas 4, 11-12 $2^{10}$ : quicquid amor iussit, non est contemnere tutum, / regnat et in dominos ius habet ille deos).

- Hercules Oetaeus, v. 357: la nodriza dice que illicita amantur, excidit quidquid licet ("se ama lo ilícito, todo lo que es lícito pierde valor"). A continuación afirma Deyanira que "la peor fortuna inflama más el amor": v. 358: Fortuna amorem peior inflammat magis; idea que desarrolla en los vv. 359-362:

Igualmente, el poder y la universalidad del amor son reconocidos en todas las tragedias: Phaedra, 218, 240, 275-357, 574-7; Agamemnon 108-9, 116-118, 134-5; Hercules furens 588; Hercules Oetaeus 539-543, 558-559; y, sobre todo, Phaedra 85128 , versos en los que Fedra hace hincapié en la fatalidad de los amores monstruosos en su familia junto a una declaración de su amor con todos los tópicos de la poesía amorosa: el insomnio de los enamorados, la comparación del amor con el fuego, la indolencia del enamorado, etc ${ }^{11}$.

3. Pero, por otro lado, al lado de la creencia tradicional en la fatalidad, la universalidad, el carácter divino de esta pasión y demás tópicos, Séneca expresa también, como ya destacó Hermann ${ }^{12}$, su propia teoría. La nodriza replica a la arrebatada confesión de pasión amorosa de Fedra (en una intervención que no tiene paralelo en el Hipólito de Eurípides):

- que el amor es un dios "es la ficción de una pasión horrible y entregada al vicio": el amor es sólo un carácter humano y la pasión ("libido") añadió a su locura el título de una falsa divinidad: Phaedra, 195-201.

Esta misma idea se encuentra en De breuitate uitae, 16, 5 y De uita beata, 26, 6 , donde afirma que con las ineptias poetarum, que presentan a Júpiter como adúltero y mujeriego, no se ha conseguido más que quitar el pudor peccandi a los hombres; y se repite en Octavia vv. 557-565 (precisamente en boca del personaje de Séneca) ${ }^{13}$ :

La idea de que el amor se alimenta en el lujo, Phaedra, 204-215, aparece en Eurípides, Danae, fr. 324; Hipólito velado, fr. 437; Hipólito, vv. 383 y ss, 409 y ss., pero desarrollada aquí por la filosofía personal de Séneca (personal con respecto a Eurípides y al estoicismo: la idea del v. 212 es contraria al estoicismo, cf. Epistulae ad Lucilium, 99, 107 y 108, 7). Es interesante observar que a partir de la pasión amorosa se ha generalizado en el planteamiento y se habla de la pasión, así libido aquí se refie-

Frente a esta vertiente del amor, Eurípides también escribió pasajes llenos de ternura dedicados al amor de la esposa, en Alcestis y fragmentos de Protesilao. Ha estudiado el amor como fuerza irracional F. Rodríguez Adrados, "El amor en Eurípides", en El descubrimiento del amor en Grecia, Madrid, 1985, pp. $177-200\left(1^{\mathrm{a}}, 1959\right)$.

9. A. Nauck-B. Snell, Tragicorum Graecorum Fragmenta, Hildesheim, 1964.

10. P. Ovidio, Heroidas, ed. F. Moya del Baño, Madrid, 1986.

11. Un estudio de los recursos lingüísticos de Fedra en M. Ruch, "La langue de la psychologie amoureuse dans la Phèdre de Sénèque", Les Ėtudes Classiques, 32, (1964), pp. 356-363. Falta por estudiar aún el interesante tema de los tópicos de la poesía amorosa en el teatro de Séneca.

12. L. Herrmann, Le Théâtre de Sénèque, París, 1924, p. 488.

13. Para la fortuna de esta concepción del amor en la literatura española, $c f$. E. del Río Sanz, $L a$ influencia del teatro de Séneca en la literatura española, Madrid, 1995 (en prensa). 
re a la pasión en general. El v. 215, típico ejemplo de sententia senecana, tan frecuente en las tragedias, con la que cierra la retórica intervención sobre la libido de la nodriza combinando tres de los temas que más le preocupaban como prosista y como político: las tentaciones del poder político, la pasión (en este caso la pasión amorosa) y los efectos de esta pasión una vez que se ha apoderado del alma de un déspota ${ }^{14}$.

- en cambio, en los los vv. 444-482 de Phaedra, la misma nodriza defiende, en el más claro ejemplo de argumentación sofística, el carácter útil y beneficioso del amor. Trata de ablandar a Hipólito y de convencerle de que cambie su vida célibe en los campos por los placeres amorosos (Hipólito no se deja convencer y responde en 89 versos con una alabanza de la vida silvestre y sus ventajas, vv. 483-564 ${ }^{15}$ ). Este pasaje se relaciona con un fragmento de una intervención del coro del Hipólito velado de Eurípides (frg. 897), pero el tratamiento es bien distinto: es difícil pensar que una nodriza dé estos consejos en un pasaje lírico en Eurípides. Entre este fragmento y el texto de Séneca hay, como señala Grimal ${ }^{16}$, toda la diferencia que existe entre una reflexión lírica y una suasoria ${ }^{17}$. Aquí la nodriza habla del carácter natural de esta pasión y propone un disfrute moderado del deseo, especialmente en los versos 446450 y $461-2$.

En los versos 466-8 alude a la providencia y juega a confundir dos conceptos del amor, como procreación y como pasión. Sigue el elogio de Venus, que se sitúa en una larga tradición literaria, que aparece ya en Eurípides (Hipólito vv. 447 y ss.; frag. 898). En la literatura latina Lucrecio trata este mismo tema en el prólogo al libro primero, pero bajo un aspecto positivo (presencia de Venus y renovación del mundo) ${ }^{18}$; en términos parecidos a los de Séneca se refiere Apuleyo, Metamorfosis 5, 28, 2 y ss. ${ }^{19}$, a la desaparición de Venus.

Para cerrar se ofrece como consejo una máxima estoica ${ }^{20}$,vv. 481-2, parodiada en provecho de esta argumentación sofística:

14. Sobre el tirano en Séneca, $c f$. H. Opelt, Der Tyrann als Unmensch in der Tragödie des L.A. Seneca, Freiburg, 1951, sobre el papel del tirano en el teatro $c f$. el insuficiente estudio de R.A. Lauer, Tyrannicide and drama, Stuttgart, 1987. Una de las características del fecundo teatro senequista español es la preferencia por colocar como figura central al terrible y cruel tirano, que es entendido como ejemplo negativo del poder político, $c f$. E. del Río Sanz, op. cit. en nota anterior.

15. Este pasaje ha sido objeto de un magnífico estudio por Vicente Cristóbal, "Edad de oro, lugar ameno y vida feliz en Fedra, 483- 564", Cuadernos de Filología Clásica, 16, (1979-1980) pp. 155-176.

16. Pierre Grimal, Sénèque. Phèdre, París, 1965, p. 85.

17. Sobre los componentes retóricos y declamatorios de las tragedias, $c f$. E. Rolland, De l'influence Sénèque le père et des rhéteurs sur Sénèque le philosophe, Gante, 1906; H. V. Canter, Rhetorical elements in the tragedies of Seneca, Illinois, 1925; G. Runchina, "Tecnica drammatica e retorica nelle tragedie di Seneca", AFLC, 28, (1960), 163-324; G.C. Giardina,Caratteri formali del teatro di Seneca, Bolonia, 1962. Un estudio de todos los trabajos dedicados a la retórica en el teatro de Séneca: G. Bonelli, "Autenticitá o retorica nella tragedia di Seneca" Latomus, 39, (1980) pp. 612-638.

18. T. Lucrecio Caro, De rerum natura, ed. de E. Valentí, t. 1, Madrid, $1983\left(1^{\text {a }}, 1962\right)$.

19. Apuleyo, Metamorfosis, ed. de D.S. Robertson-P. Vallette, París, Les Belles Lettres, 3 t., 1956-8.

20. M. Tulio Cicerón, De officiis, ed. M. Testard, París, 2 t.,Les Belles Lettres, 1, 100 y ss., afirma que el primer deber es el de procurar una plena y constante armonía con las leyes de la naturaleza, porque 
proinde uitae sequere naturam ducem: urbem frequenta, ciuim coetus cole

4. ¿Y los remedia amoris? Como decíamos supra, Séneca no suele ofrecer remedios en las tragedias: tan sólo en Phaedra vv. 132-5 plantea la solución frente a la pasión amorosa, pasaje que se relaciona con el ovidiano principiis obsta, sero medicina paratur, / cum mala per longas conualuere moras (Remedia amoris, vv. 91-2 ${ }^{21}$; también Heroidas 17, vv. 191-2: dum nouus est, potius cepto pugnemus amori; /flamma recens parua sparsa resedit aqua), pero es un pensamiento casi tópico en las obras en prosa de Séneca, donde insiste en la doctrina de los estoicos, para quienes se deben combatir y eliminar las pasiones sobre todo en sus comienzos (Epistulae ad Lucilium 116, 3; Epistulae ad Lucilium 85,9; Epistulae ad Lucilium 85, 28; Consolatio ad Marciam 1, 7; De tranquilitate animi 10,5; De ira, 1, 7, 2; y especialmente el texto del De ira, 1, 7, 4, en el que compara la evolución de las pasiones con un cuerpo lanzado al vacío, y que una vez arrojado no puede pararse ni volver atrás. Cicerón, Tusculanae, $4,41^{22}$ utiliza un ejemplo parecido al referirse también a la imposibilidad de controlar un vicio)

5. Se plantea, en fin, en las tragedias de Séneca, como señala J. Luque, la lucha entre la razón y la pasión: "lo trágico surge de la lucha que en el interior del hombre se entabla entre fuerzas contrarias" ${ }^{\prime 23}$. Los dramas senecanos llevan al escenario los malos efectos de las pasiones para educar al espectador (y ésta la gran diferencia con la tragedia griega, que no pretende moralizar al espectador). Séneca está convencido de que el hombre tiene libertad de ejercer entre el bien y el mal y que puede reaccionar contra sus malas inclinaciones o contra una herencia perniciosa, pero una vez vencido el ánimo por la pasión amorosa el cuerpo cae inevitablemente al vacío: la libertad se subordina a la pasión, es el caso de Fedra, Medea, Clitemnestra, Deyanira. Como adelantábamos al principio, y hemos podido comprobar en las páginas precedentes, mientras el Séneca prosista combate las pasiones con el estoicismo, las tragedias no van más allá de presentarlos, y apenas se alude a los remedios contra el mal: el aspecto positivo de la doctrina estoica es raro en las tragedias, aunque la actitud mental de Séneca como estoico ejerce una influencia directa en su obra en casi todos los aspec-

si se toma ésta como guía, además de seguir el camino recto se conseguirán tres virtudes en las que insiste en la obra: agudeza mental, conducta conforme a la convivencia civil, vigor y energía de carácter: officium autem quod ab eo ducitur, hanc primum habet uiam quae deducit ad conuenientiam conseruationemque naturae. Es una idea querida por Séneca, para quien el sabio vivirá preferentemente en el campo, en medio de la naturaleza, $c f$. L. Herrmann, op. cit. en n. 10, pp. 501-2. Para el transfondo filosófico de Phaedra $c f$. J.M. Croisille, "Lieux communs, sententiae et intentions philosophiques dans la Phèdre de Sénèque", REL, 42, (1964), pp. 276-301; E. Lefévre, "Quid ratio possit? Senecas Phaedra als stoiches Drama", Wiener Studien, 3, (1969), 131-160.

21. P. Ovidio, Remedia Amoris, ed. E.J. Kenney, Oxford, 1977 (1ª 1961).

22. M. Tulio Cicerón, Tusculanae disputationes, ed. M. Pohlenz, Leipzig, 1918.

23. J. Luque, ed. cit. en n. 1, t. 1, p. 32. 
tos. Como señala el prof. Luque, "es ese hombre y son esas pasiones lo que parece interesar a Séneca por encima de todo, incluso por encima de las propias doctrinas filosóficas" ${ }^{24}$.

Un estudio, en fin, en profundidad de los distintos temas de las tragedias de Séneca -entre los que el amor ocupa un lugar importante y del que en estas páginas hemos querido dibujar unas pinceladas básicas como apoyo a posteriores investigaciones- ayudará a dilucidar bien el papel que tienen la tragedia griega, el fondo doctrinal estoico, el eclecticismo senecano, la función didáctica, la retórica, etc., en estas obras que, como bien señala Herington, "son la expresión única de una mente extraordinaria, una mente sensible como pocas lo han sido a los problemas espirituales y políticos de la condición humana"25. 